\title{
Michael TOCH, (éd.), Elisabeth MÜLLER-LUCKNER, (collab.), Wirtschaftsgeschichte der mittelalterlichen Juden. Fragen und Einschätzungen
}

München, R. Oldenbourg Verlag, coll. «Schriften des Historichen Kollegs. Kolloquien», 71, 2008, 218 p.

\section{Andrei Timotin}

\section{OpenEdition}

Journals

Édition électronique

URL : http://journals.openedition.org/assr/22493

DOI : $10.4000 /$ assr.22493

ISSN : $1777-5825$

Éditeur

Éditions de l'EHESS

Édition imprimée

Date de publication : 31 décembre 2010

Pagination : 9-242

ISBN : 9782713223013

ISSN : 0335-5985

\section{Référence électronique}

Andrei Timotin, « Michael TOCH, (éd.), Elisabeth MÜLLER-LUCKNER, (collab.), Wirtschaftsgeschichte der mittelalterlichen Juden. Fragen und Einschätzungen », Archives de sciences sociales des religions [En ligne], 152 | octobre-décembre 2010, document 152-113, mis en ligne le 06 mai 2011, consulté le 21 septembre 2020. URL : http://journals.openedition.org/assr/22493 ; DOI : https://doi.org/10.4000/ assr.22493

Ce document a été généré automatiquement le 21 septembre 2020.

(c) Archives de sciences sociales des religions 


\section{Michael TOCH, (éd.), Elisabeth MÜLLER-LUCKNER, (collab.), Wirtschaftsgeschichte der mittelalterlichen Juden. Fragen und Einschätzungen}

München, R. Oldenbourg Verlag, coll. «Schriften des Historichen Kollegs. Kolloquien», 71, 2008, 218 p.

\section{Andrei Timotin}

\section{RÉFÉRENCE}

Michael тосн, (éd.), Elisabeth MÜLLER-LUCKNER, (collab.), Wirtschaftsgeschichte der mittelalterlichen Juden. Fragen und Einschätzungen, München, R. Oldenbourg Verlag, coll. «Schriften des Historichen Kollegs. Kolloquien», 71, 2008, 218 p.

L'histoire économique des juifs au Moyen Âge est marquée par une double isolation. D'une part, elle l'est par rapport à l'histoire économique globale qui ignore, en général, les sources hébraïques. Malgré le rôle économique incontestable des juifs, il n'y a pas d'histoire économique générale du Moyen Âge qui tienne compte de cet aspect. D'autre part, l'histoire générale des juifs ne se rapporte que très rarement à l'histoire économique générale, l'aspect économique étant traité le plus souvent comme l'expression d'une particularité juive. C'est pour remédier à ces inconvénients que Michael Toch a réuni à Munich, en juin 2005, des chercheurs d'Allemagne, du RoyaumeUni, d'Israël, des États-Unis, d'Italie et d'Autriche autour du thème «L'histoire économique des Juifs au Moyen Âge». Les objectifs principaux de cette réunion scientifique étaient d'étudier l'histoire économique des communautés juives dans diverses régions de l'Europe médiévale et d'éclairer une série de questions centrales 
pour cette thématique comme l'attitude à l'égard de l'usure dans la pensée religieuse juive, le commerce de livres, les hôpitaux juifs, les activités économiques des femmes.

Dans l'article qui ouvre le recueil d'études issu de cette réunion («Christian Perceptions of Jewish Economic Activity in the Middle Ages»), Giacomo Todeschini met en question un des plus communs et des plus répandus stéréotypes élaborés par la culture chrétienne médiévale: l'image du juif usurier. L'auteur examine les sources ecclésiastiques sur lesquelles est fondé le sens attribué à la notion d'usura dans la culture chrétienne médiévale et montre les ambiguïtés et les contradictions de l'attitude de l'Église à l'égard des notions de crédit, d'intérêt et, en général, de richesse monétaire après la révolution économique des $\mathrm{XI}^{\mathrm{e}}-\mathrm{XII}^{\mathrm{e}}$ siècles. Le stéréotype du juif usurier recoupe le rejet global des initiatives économiques non ecclésiastiques (bonum particulare) susceptibles de faire péricliter la richesse de l'Église, tandis que les théoriciens du droit ecclésiastique développent aux XII ${ }^{\mathrm{e}}$-XIII ${ }^{\mathrm{e}}$ siècles une définition de la légitimité des Églises d'opérer des transactions de crédit par l'achat ou la vente des revenus périodiques (bonum commune).

D'autre part, dans la culture économique juive, ignorée par les auteurs chrétiens, le prêt à intérêt n'est pas interdit si l'emprunteur n'est pas juif, comme le souligne l'étude de Hans-Georg von Mutius, "Taking Interest from Non-Jews - Main Problems in Traditional Jewish Law», qui analyse des sources hébraïques comme la Mishna, le Talmud babylonien, le Tosefta (Talmud palestinien) et la littérature midrashique. L'usure n'exclut pas les objets chrétiens de culte, comme le rappelle Joseph Shatzmiller («Church Articles: Pawns in the Hands of Jewish Moneylenders»). Un document hébraïque de première main exploite Annegret Holtmann («Medieval "Pigeonholes". The Jewish Account Books from Vesoul and Medieval Bookkeeping Practices»): il s'agit de deux livres de comptes d'une compagnie commerciale juive dont le siège était à Vesoul, en Franche-Comté, qui représentent une des sources les plus importantes pour le commerce juif médiéval de livres et parmi les premiers livres de comptes privés au Nord des Alpes.

4 Une série de trois études examinent les activités économiques des juifs dans des espaces géographiques différents, comme l'Empire byzantin, la Sicile et l'Italie de Sud et les domaines maritimes vénitiens. David Jacoby étudie l'activité économique des juifs byzantins à l'époque Paléologue en relation avec l'économie des territoires exbyzantins occupés par les Latins après la quatrième croisade, qui a produit une restructuration des réseaux commerciaux dans la Méditerranée orientale et a affecté profondément l'économie byzantine («The Jews in Byzantium and the Eastern Mediterranean: Economic Activities from the Thirteenth to the Mid-Fifteenth Century»). Fondée notamment sur les sources vénitiennes et génoises, cette enquête montre qu'il n'y a pas eu à Byzance d'activité économique exclusivement réservée aux juifs, à part les fonctions rituelles, et que les juifs étaient plutôt bien intégrés dans la production, la manufacture et les réseaux commerciaux de Byzance et de la Romania latine, à des degrés qui varient selon les conditions locales. Le régime fiscal lourd qui leur est imposé aux XIV ${ }^{e}$ et $\mathrm{XV}^{\mathrm{e}}$ siècles a pourtant limité drastiquement le capital disponible pour les investissements commerciaux, et les restrictions concernant l'acquisition de domaines ont encouragé et conduit progressivement à la spécialisation des juifs dans les opérations de prêt financier qui deviennent leur secteur économique de référence dans la Crète vénitienne. 
David Abulafia compare les activités économiques des juifs de Sicile avec celles des juifs de l'Italie de Sud, sur la base des archives de la Genizah du Caire pour le haut Moyen Âge, et des documents notariaux pour le Moyen Âge tardif («The Jews of Sicily and Southern Italy: Economic Activity»). Il apparaît que les communautés juives à la fin du Moyen Âge sont économiquement beaucoup moins puissantes qu'elles n'apparaissent à l'époque des archives de la Genizah, mais l'auteur souligne l'importance du rôle des juifs dans l'essor économique de la Sicile et de l'Italie de Sud au Xve siècle, jusqu'à leur expulsion de ces territoires respectivement en 1492, par Ferdinand, et en 1531, par CharlesV et son vice-roi Pedro de Toledo.

Reinhold C. Mueller tire profit d'une série d'études récentes sur l'histoire des juifs de la Terraferma vénitienne dans le dernier siècle du Moyen Âge pour dresser une image contrastée des activités économiques des juifs dans les domaines maritimes vénitiens («The Status and Economic Activity of Jews in the Venetian Dominions during the Fifteenth Century»). Par rapport aux communautés juives de la Terraferma, celles des domaines maritimes, notamment de Crète et de Corfou, sont dix fois plus nombreuses et jouissent de privilèges: à Corfou les juifs ont le statut de citoyens permanents. L'auteur montre que, dans ces territoires, ils exercent sans restrictions des activités économiques diverses (commerce, artisanat, etc.)

7 Les dernières contributions du volume portent sur les activités économiques des juifs des pays allemands (les Ashkénazes) au Moyen Âge, thème auquel l'éditeur du volume, Michael Toch, consacre une étude de synthèse remarquable («Economic Activities of German Jews in the Middle Ages»), fruit d'une recherche commencée depuis longtemps et scandée déjà par de nombreuses publications. Markus J. Wenninger examine leurs métiers de monetarius, de douanier et de haut fonctionnaire du fisc («Juden als Münzmeister, Zollpächter und fürstliche Finanzbeamte in mittelalterlichen Aschkenas»), Rainer Barzen établit l'histoire médiévale de la Zedaka (la caritas juive) en étudiant le développement des associations charitables (les chevrot) et des premiers hôpitaux juifs («"Was der Arme benötigt, bist Du verpflichtet zu geben”. Forschungsansätze zur Armenfürsorge in Ashkenas im hohen und späten Mittelalter»), et Martha Keil explore l'univers économique et social des femmes («Mobilität und Sittsamkeit: Jüdische Frauen im Wirtschaftsleben des spätmittelalterlichen Aschkenas»).

8 Considérées en bloc, les contributions réunies dans ce volume recomposent une image fournie de l'histoire économique des juifs au Moyen Âge, formée des histoires locales inévitablement dépendantes de la richesse ou, au contraire, de l'absence des archives. La qualité et la cohérence des contributions compensent l'absence des études (souhaitables) sur les communautés juives de la Péninsule ibérique, de la France et du Royaume-Uni et récompensent le travail remarquable à tout point de vue de l'éditeur. 